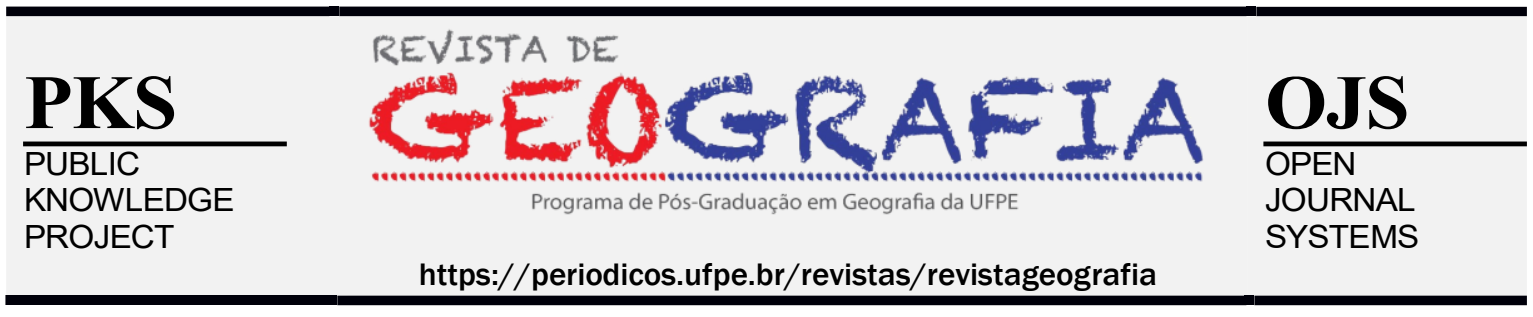

\title{
RESIDÊNCIA PEDAGÓGICA E A GEOGRAFICIDADE: EXPERIÊNCIAS VIVENCIADAS NA ESCOLA MUNICIPAL JOÃO COSTA DE OLIVEIRA, EM UNIÃO DOS PALMARES - AL
}

\author{
José Lidemberg de Sousa Lopes ${ }^{1}$, Milena Gomes Lima ${ }^{2}$, Rafael de Lima Silva ${ }^{3}$, \\ Marta Celina Linhares Sales
}

\begin{abstract}
${ }^{1}$ Universidade Estadual de Alagoas (UNEAL). E-mail: lidemberg.lopes@uneal.edu.br; Orcid: https://orcid.org/0000-0003-1295-2124

${ }^{2}$ Universidade Estadual de Alagoas (UNEAL). E-mail: miihgomes@gmail.com; Orcid: https://orcid.org/0000-0003-2131-6525

${ }^{3}$ Universidade Estadual de Alagoas (UNEAL).E-mail:rafaellima2017@gmail.com; https://orcid.org/00000003-1609-5836

${ }^{4}$ Universidade Federal do Ceará (UFC). E-mail: mcls@uol.com.br; Orcid: https://orcid.org/0000-00027334-3587
\end{abstract}

Artigo recebido em 17/05/2021 e aceito em 04/10/2021

\begin{abstract}
RESUMO
O presente artigo tem como objetivo divulgar experiências vivenciadas na Escola Municipal João Costa de Oliveira, em União dos Palmares - AL. A escola foi uma das contempladas com o Programa Residência Pedagógica, cujo o subprojeto fico intitulado "Territorialidade e Resistência - entreolhares para formação docente e a prática pedagógica no município de União dos Palmares - AL". Como base da pesquisa, usamos as categorias geográficas de lugar e paisagem, e o conceito de Geograficidade, de Eric Dardel (2015), em sua principal obra: O Homem e a Terra: natureza da realidade geográfica. $\mathrm{O}$ trabalho tem sua estrutura baseada em uma metodologia qualitativa, cujo método (fenomenológico) proporcionou nossa imersão no ambiente escolar e nos deu acesso às concepções acerca da Geografia presente no dia-a-dia dos alunos do $6^{\circ}$ ano "D". Como resultados da pesquisa foram elaboradas atividades sempre levando em consideração dos conteúdos abordados no livro de geografia: Expedições geográficas/ Melhem Adas, Sergio Adas. 2. Ed. - São Paulo: Moderna, 2015. As atividades usadas para a elaboração deste trabalho foram: construção de Quebra-cabeça, elaboração de cartaz, como construir uma bússola caseira, desenhar e usar uma rosa-dos-ventos, exibir mapas e construir mapa mental, uso dos aplicativos Google Maps e Google Earth, jogo de campo minado, elaboração de geoides. maquete do sistema solar; e construção e exposição de vulcões. Concluímos que realizar atividades de cunho interativo motivam os discentes, enquanto eles se divertem com o objetivo de aprender determinados conteúdos geográficos.
\end{abstract}

Palavras-chave: Paisagem; Lugar; Interatividade; Ludicidade; Livro didático. 


\title{
PEDAGOGICAL RESIDENCY AND GEOGRAPHY: EXPERIENCES LIVED AT THE JOÃO COSTA DE OLIVEIRA MUNICIPAL SCHOOL, IN UNIÃO DOS PALMARES - AL
}

\begin{abstract}
This article aims to disseminate experiences lived at the João Costa de Oliveira Municipal School, in União dos Palmares - AL. The school was one of those included in the Pedagogical Residency Program, whose subproject is entitled "Territoriality and Resistance entreolhares for teacher training and pedagogical practice in the municipality of União dos Palmares - AL". As a basis for the research, we used the geographical categories of place and landscape, and the concept of Geography, by Eric Dardel (2015), in his main work: The Man and the Earth: nature of the geographical reality. The work has its structure based on a qualitative methodology, whose method (phenomenological) provided our immersion in the school environment and gave us access to the conceptions about Geography present in the day-to-day life of 6th grade students " $D$ ". As a result of the research, activities were developed, always taking into account the contents covered in the geography book: Geographical expeditions/Melhem Adas, Sergio Adas. 2. Ed. - São Paulo: Moderna, 2015. The activities used for the elaboration of this work were: puzzle construction, poster elaboration, how to build a homemade compass, draw and use of a compass rose, displaying of maps and building of mind map, use of Google Maps and Google Earth applications, minefield game, geoid development, model of the solar system; and construction and exposure of volcanoes. We conclude that performing interactive activities motivate students, while they have fun with the goal of learning certain geographical contents.
\end{abstract}

Keywords: Landscape. Place. Interactivity. Playfulness. Textbook.

\section{INTRODUÇÃO}

Nem toda pesquisa se conclui com resultados rápidos, algumas demoram meses e até mesmo anos para chegar em sua forma mais coesa, é necessário aguardar a germinação das sementes da ciência, no espaço escolar, nas universidades e nos centros de pesquisa para que elas se frutifiquem ao longo do tempo.

Durante um ano e meio, bolsistas, voluntários, preceptores e coordenador planejaram e realizaram mediações nas salas de aula da Escola Municipal João Costa de Oliveira, com o objetivo de conduzir os alunos dos sextos anos com faixa etária entre $10 \mathrm{e}$ 13 anos, aos principais pontos da ciência geográfica, analisando do todo à realidade vivenciada pelos alunos, em diversas escalas.

$\mathrm{O}$ artigo tem sua estrutura baseada em uma metodologia qualitativa, cujo método (fenomenológico) proporcionou nossa imersão no ambiente escolar e nos deu acesso às concepções acerca da Geografia presente no dia-a-dia dos alunos do $6^{\circ}$ ano "D" da escola anteriormente supracitada. Para a elaboração deste projeto pedagógico/geográfico, foram necessárias as formulações das seguintes etapas estruturais: 
- Em primeiro lugar, descrevemos o programa, o projeto e os objetivos almejados por todos os empenhados, incluindo a escola onde ocorreram as atividades.

- Em seguida, planejamos um tópico para mostrar o planejamento de algumas das atividades realizadas ao longo do projeto e mencionando alguns possíveis problemas que acontecem diariamente na realidade das unidades municipais educacionais do ensino fundamental II do país. Baseados em conceitos de Silva e Camargo (2015) e de Tuan (2013), afim de compreender as drásticas variações que ocorrem na mudança do Ensino Fundamental I para o Ensino Fundamental II para os alunos, enquanto os docentes se desdobram para facilitar a aprendizagem, usando técnicas de transposição didática, utilizadas devido ausência de recursos metodológicos presentes na instituição de ensino.

- Complementamos a pesquisa com os resultados das atividades expostas, e levando em conta que muitos dos alunos vivem em localizações consideradas periféricas, carregando um estigma de que não há futuro para eles, concluímos a pesquisa com resultados positivos.

A geografia nos mostrou que além de futuros brilhantes, os alunos possuem níveis cognitivos e criativos elevados, graças as ações didáticas pedagógicas aplicadas pelos bolsistas. Por fim, conceitos geográficos podem trazer estranheza para as turmas, mas tudo muda quando passam a ser interpretados, aplicados e vivenciados cotidianamente pelos alunos.

\section{RESIDÊNCIA PEDAGÓGICA NO CAMPUS V EM UNIÃO DOS PALMARES/AL}

As experiências vivenciadas no processo de formação docente influenciam diretamente na constituição profissional. Teoria e prática andam juntas no decorrer desse processo, possibilitando a construção de um pensamento autônomo, solidário e competente, capaz de enfrentar os desafios contemporâneos destinados a escola. Segundo GATTI (2009) a formação continuada foi proposta como requisito fundamental ao trabalho docente em consequência do crescimento na produção do conhecimento, das tecnologias e também das mudanças no trabalho, sendo compreendida como uma atualização e aprofundamento com vistas ao desenvolvimento profissional.

Complementando Gatti, TARDIF (2000) vai além, ele salienta que ao falar sobre saberes das disciplinas, saberes curriculares, saberes da formação docente e os saberes da 
experiência, caberá ao professor entender suas ações e mobilizar diversos saberes para o ensinar.

Para que isso ocorra de forma concisa e duradoura, torna-se necessário dialogar com diferentes conhecimentos, agregando uma visão ampla embasada em processos de ensino e aprendizagem voltados à formação de competências. Esta visão interdisciplinar permite ao licenciando mobilizar conhecimentos que conduzam a uma reflexão mais profunda acerca da realidade, além de capacitá-lo no enfrentamento dos possíveis dilemas encontrados no dia a dia da sala de aula.

De acordo com Batista e Pinheiro (2019):

\begin{abstract}
Questionar-se sobre suas práticas deve ser uma constante na vida dos professores, assim como atentar-se para o que se ensina, como ensina, avaliar e reavaliar como tem sido a aprendizagem de seus alunos. Portanto, é necessário, por parte do docente, repensar as teorias e as práticas de ensino-aprendizagem. Esse processo não é fácil, porém é necessário, pois nos faz questionar as certezas e, assim, raspar as tintas, nos faz compreender que existe mais produção de conhecimento quando fazemos outras pinturas e nos reinventamos (BATISTA e PINHEIRO, 2019, p. 64).
\end{abstract}

A partir desta compreensão, as atividades propostas para o Programa Residência Pedagógica com o subprojeto intitulado "Territorialidade e Resistência - entreolhares para formação docente e a prática pedagógica no município de União dos Palmares - AL", vieram para estabelecer um diálogo transitório com os saberes referentes ao componente curricular geografia, sem, contudo, negligenciar a interligação entre os diferentes saberes presentes nas estruturas curriculares da escola. Neste sentido as atividades do Projeto Residência Pedagógica, foram realizadas seguindo as orientações dispostas na Base Nacional Comum Curricular, a BNCC, para o componente geografia, na busca de desenvolver o pensamento espacial do aluno, estimulando o raciocínio geográfico, respeitando os princípios de analogia, conexão, diferenciação, distribuição, extensão, localização e ordem.

O subprojeto foi dividido em etapas que foram realizadas da seguinte forma: a) Curso de formação de preceptores, com duração de dois meses; b) Orientação conjunta entre coordenação, preceptores das escolas e os residentes, com duração de 04 meses; c) Imersão e atuação dos residentes nas escolas, etapa que teve duração de 10 meses.

Estes princípios possibilitaram aos residentes e aos alunos das "escolas campo" dialogarem sobre os principais conceitos geográficos e o uso deles em suas experiências vividas, como lugar e paisagem, todo o espaço geográfico em sala de aula. Ações que foram 
de encontro à mera descrição da realidade, permitindo aprofundarem discussões por meio da compreensão da realidade de forma ampla e crítica.

Batista e Pinheiro (2019, p. 72) afirmam que: "teoria e prática são faces da mesma moeda e, assim, nenhuma delas será produtiva se realizada de forma isolada”. E esse foi o intuito do Programa Residência Pedagógica no Campus V da Universidade Estadual de Alagoas, para que seus discentes, futuros docentes tenham experiências na prática com toda teoria adquirida durante o curso, qualificando-os para o futuro profissional.

Para Kaercher (2014. p. 42): “a matéria-prima para nossas aulas está no mundo, na vida mesma de nossos alunos" e as atividades encontradas no presente trabalho foram vivenciadas na Escola Municipal João Costa de Oliveira, no município de União dos Palmares, uma das três escolas escolhidas para a realização do projeto.

Fundada em 1972, na gestão do prefeito Manoel Gomes de Barros, a escola recebeu o nome de Escola Municipal Jatobá. Em 1977 assumiu seu atual nome, em homenagem ao Sr. João Costa de Oliveira, doador do terreno onde a escola foi construída através do projeto encabeçado pelos moradores, juntamente com alguns vereadores do município. As famílias que residiam na época, uma grande parcela quilombolas, encontravam na escola não apenas conhecimento, mas apoio nas reinvindicações, petições de auxilio, dentre outras atividades que visavam melhorias coletivas. Entretanto, em junho de 2010, com a enchente que atingiu a região, a Escola foi totalmente destruída. Uma parte da memória do local ficou resguardada nos objetos e artefatos resgatados por alguns moradores que conseguiram ter acesso ao interior da escola nas horas que antecederam o aumento do volume de água do rio Mundaú.

Apenas dois anos após este ocorrido, em regime de cooperação mútua, os moradores conseguiram uma nova instalação, a escola foi instalada na antiga Escola Cenecista. Os moradores não mediram esforços nas ações para recuperar o local de referência e convivência de toda população local. Hoje, a Escola Municipal João Costa de Oliveira, está localizada no Conjunto Habitacional Newton Pereira Gonçalves (Figura 1), e oferece as seguintes modalidades de ensino: Ensino Fundamental I - $1^{\circ}$ ao $4^{\circ}$ ano, turno matutino; o Ensino Fundamental II - $6^{\circ}$ ao $9^{\circ}$ ano, turno vespertino e EJA - Educação de Jovens e Adultos - $1^{\mathrm{a}}$ e $2^{\mathrm{a}}$ fase, no turno noturno, atendendo 1.511 alunos. Possui um quadro composto por 94 funcionários, e a infraestrutura da escola após a enchente foi completamente modificada. Atualmente a escola conta com amplas salas de aula, salas de informática, quadra de esportes e um espaço dedicado ao artesanato local. 
Figura 1 - Localização atual da Escola Municipal João Costa de Oliveira em União dos Palmares, AL

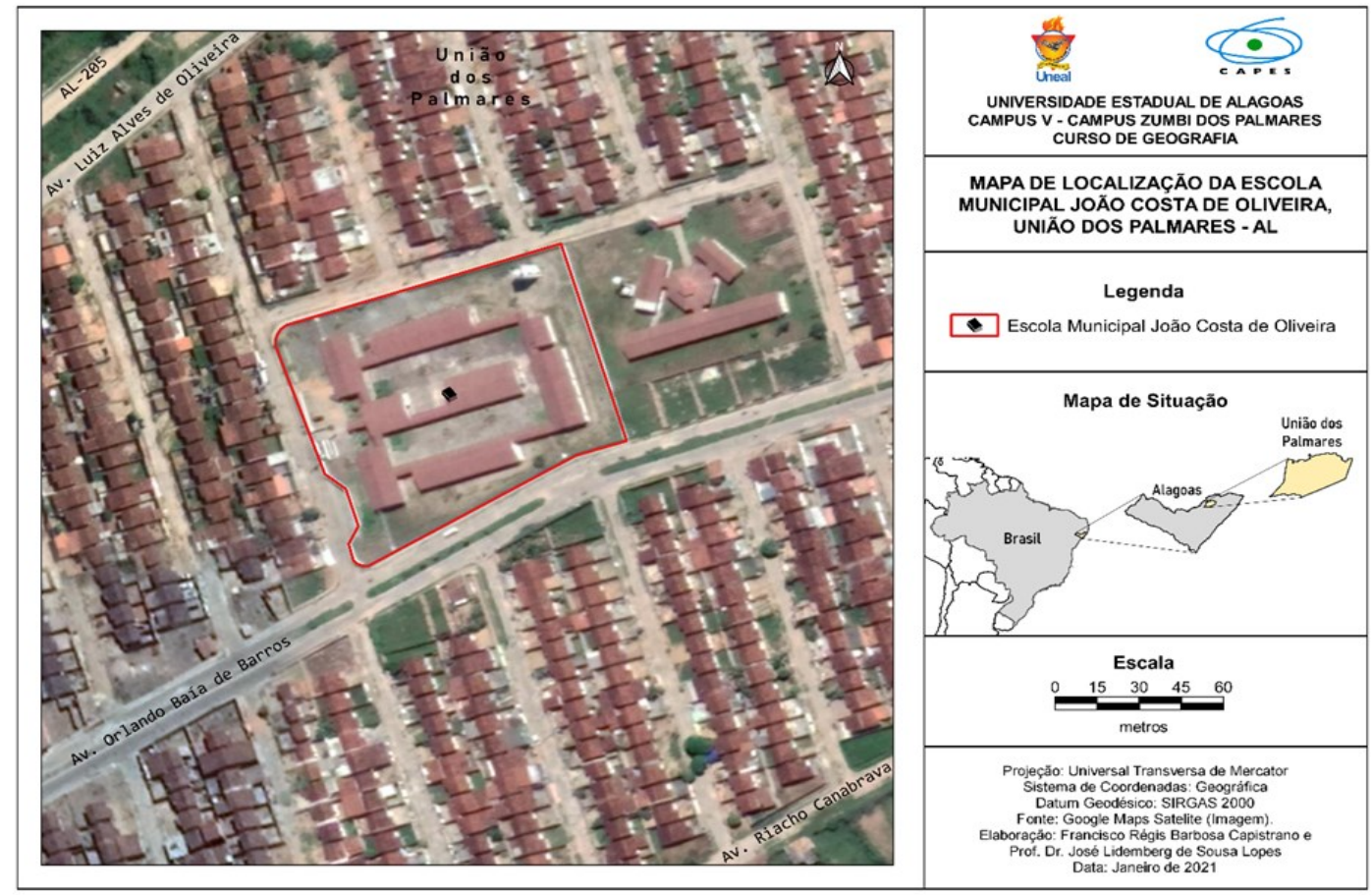

Fonte: Google Maps Satélite (Imagem), janeiro de 2021.

A direção da escola abriu as portas para o Programa Residência Pedagógica do Curso de Licenciatura Plena em Geografia da Universidade Estadual de Alagoas, engajando professores e alunos na elaboração do projeto. Vale ressaltar que o campus V da Universidade Estadual de Alagoas já vem discutindo com a comunidade escolar a Base Nacional Comum Curricular, destinada aos anos iniciais, bem como ao Ensino Fundamental II. Uma parceria universidade e escola, desenvolvido via projeto de extensão, uma experiência que encontra no projeto de Residência Pedagógica uma maior possibilidade de alcance na discussão da BNCC, bem como um maior envolvimento dos licenciandos, a comunidade escolar e a população no geral. Partindo das ações pedagógicas, tem-se a clareza de que ensinar não é repassar conteúdos prontos, ou seja, requer do professor o constante repensar de sua prática. Criar, inovar, inventar e reinventar formas mais eficientes no alcance de uma aprendizagem significativa.

Oliveira (2014. p. 108) observa que: “a construção do conhecimento ocorre, efetivamente, no espaço vivido e percebido dos sujeitos. É nesse que se desvelam os contextos sociais, político, econômico e científico. É nesse que a comunicabilidade de indivíduos se articula, estabelecendo relações interculturais. É nesse espaço que às existências geográficas se manifestam" e O Conjunto Habitacional Newton Pereira 
Gonçalves é o espaço vivido dos alunos. O bairro é novo para o município, distante do centro da cidade e com boa parte da população carente. Foi neste espaço em que foram abordadas diversas situações durante o projeto, que mostrassem um pouco da realidade dos que ali residem, trazendo exemplos que foram observados ou puderam ser explorados na comunidade, valorizando o espaço vivido dos alunos.

\section{METODOLOGIA}

As atividades realizadas foram baseadas nas primeiras unidades do livro didático de geografia, que foi analisado previamente pelo corpo docente da escola e aprovado posteriormente. O livro usado foi o EXPEDIÇÕES GEOGRAFICAS, de autoria de Melhen Adans e Sérgio Adans, na figura 2.

Os primeiros conteúdos dentro das unidades foram exatamente sobre a interrelação de paisagem, lugar e cartografia como categorias do espaço geográfico. A turma na qual aplicamos as atividades foi a do $6^{\circ}$ ano "D" do Ensino Fundamental II, com alunos de faixa etária entre 10 e 13 anos de idade, visto que essa é uma das fases mais complicadas para os alunos, a transição do Ensino Fundamental I para o Ensino Fundamental II, onde os jovens adentram em um ambiente mais complexo de ensino, com mudanças drásticas que vão da forma de lidar com diferentes professores até os conteúdos das próprias disciplinas. De acordo com Tuan (2013, p. 45): “O horizonte geográfico de uma criança expande à medida que ela cresce, mas não necessariamente passo a passo em direção à escala maior. Seu interesse e conhecimento se fixam primeiro na pequena comunidade local, depois a cidade, saltando o bairro; e da cidade seu interesse pode pular para a nação e para lugares estrangeiros, saltando a região. [...] ela não se prende ao que vê ou sente em sua casa e em seu bairro". 
Figura 2 - Livro didático escolar, Expedições Geográficas, $6^{\circ}$ ano, editora Moderna, 2015

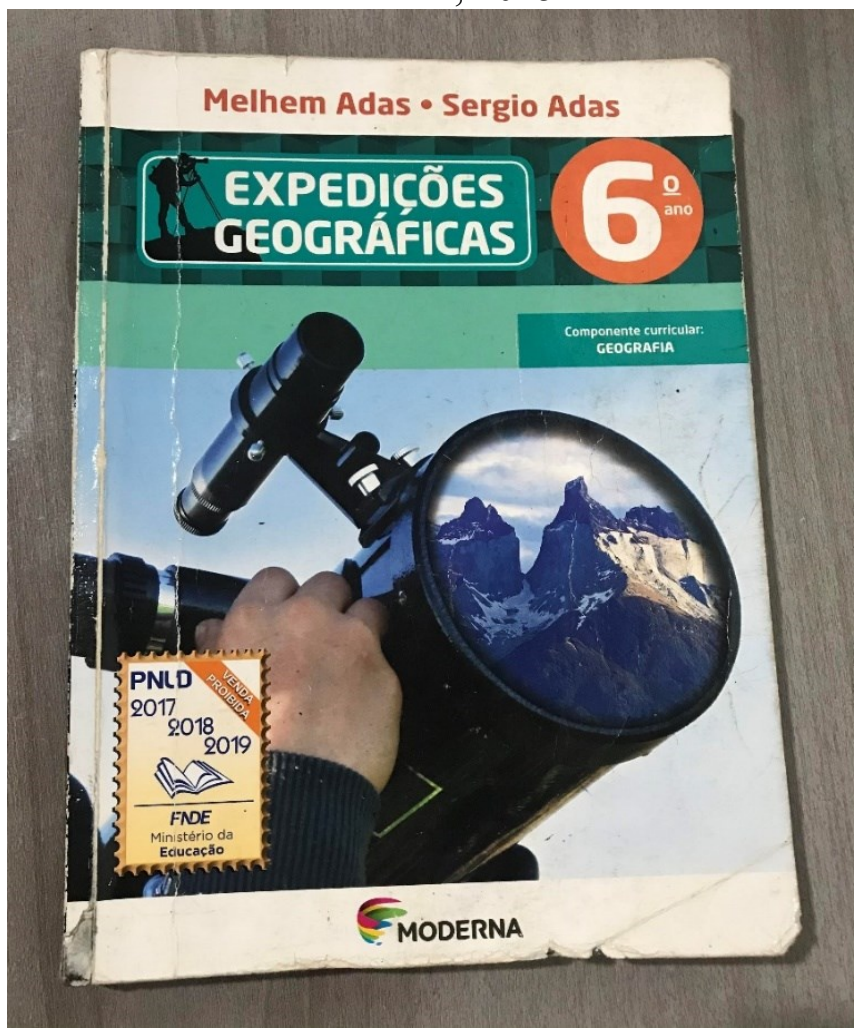

Fonte: Lima, M.G, 2021.

Imaginemos então o que se passa na fase de transição destes alunos: já não "podem" mais sentar no chão; as cadeiras são enfileiradas; já não têm apenas um professor; e para completar, eles devem manter a "postura" em sala. É de suma importância a inclusão e acolhimento de discentes que possuem perfis diferentes se tratando de sala de aula: alunos que apresentam diversos perfis cognitivos e comportamentais que não corroboram para uma sadia e proveitosa absorção de e da aprendizagem. Em muitas das vezes, esses alunos não possuem estrutura familiar para que os estimulem, diversas vezes professores vão além das atividades escolares e agem como pais, psicólogos, e/ou amigos desses alunos. O ambiente escolar deve ser um espaço educativo, mas não consegue se manter sozinho.

Segundo Silva e Camargo (2015): "Sendo assim, a escola é o lugar onde os alunos deveriam exercitar a cidadania, a autonomia, a criticidade, a responsabilidade, construindo seu conhecimento moral procedimento e conceitual; mas eles veem o colégio como um ponto de encontro para ver colegas, "paquerar", desfilar roupas ou o novo celular. Haveria uma forma de tornar estas duas funções não excludentes, e sim complementares?”.

Essas observações são apenas o início da principal problemática encontrada em sala de aula por meio de observações durante a realização de atividades, que é a interpretação dos conteúdos iniciais da Geografia, que vêm carregados de conceitos da 
“Geografia Física”. Tais como espaço e paisagem, orientação no espaço geográfico, representação da Terra, escala, agentes internos e externos do relevo, etc., difíceis até mesmo de serem compreendidos no espaço acadêmico.

A metodologia ativa ${ }^{1}$ aplicada pelo professor preceptor e pelos bolsistas, parte do princípio do vivido e da experiência de cada aluno, seu bairro, escola e cidade. O lugar pode adquirir profundo significado devido ao caráter experiencial e a Geografia tem este papel na educação: estudar as interações que ocorrem na produção do espaço. Nosso trabalho sempre lidou com a realidade de cada aluno em sala, usando diversas estratégias pedagógicas para fugir da realidade monótona que é a rotina de uso do quadro branco e livro didático.

\section{Etapas das confecções das atividades aplicadas em sala de aula}

Seguindo os conteúdos trazidos no livro didático usado pela escola para a turma contemplada com o projeto: Expedições Geográficas, foram apresentadas propostas de materiais didáticos para serem colocados em prática na sala de aula, em forma de metodologias ativas, para melhor desempenho dos alunos. Segue o quadro com algumas das atividades realizadas.

Quadro 1 - Atividades elaboradas em sala de aula pelos residentes

\begin{tabular}{|c|l|l|}
\hline $\begin{array}{c}\text { Conteúdo do livro } \\
\text { didático }\end{array}$ & Atividade elaborada & Materiais utilizados \\
\hline Espaço e Paisagem & \multicolumn{1}{|c|}{ Quebra-cabeças e cartaz } & $\begin{array}{l}\text { Imagens de lugares importantes para a } \\
\text { cidade, inclusive da escola de atuação, } \\
\text { recortadas, cola, papel A4 e cartolina. }\end{array}$ \\
\hline $\begin{array}{c}\text { Orientação no espaço } \\
\text { geográfico }\end{array}$ & $\begin{array}{l}\text { Bússola caseira; } \\
\text { Como desenhar e usar uma Rosa } \\
\text { dos Ventos; } \\
\text { Exposição de mapas. }\end{array}$ & $\begin{array}{l}\text { Recipiente com água, agulha, papel } \\
\text { higiênico e lã de aço; Quadro branco e } \\
\text { caneta para quadro branco; Mapas do } \\
\text { Brasil e do mundo expostos no chão; }\end{array}$ \\
\hline $\begin{array}{c}\text { Cartografia, do desenho ao } \\
\text { mapa e a representação da } \\
\text { Terra; }\end{array}$ & $\begin{array}{l}\text { Exposição de diversos tipos de de } \\
\text { mapa; Elaboração de mapas } \\
\text { metais pelos alunos; Imagens do } \\
\text { Google Earth e Google Maps; }\end{array}$ & $\begin{array}{l}\text { Imagens de mapas dos mais diversos } \\
\text { tipos expostos em apresentações de } \\
\text { slide e imagens do aplicativo Google } \\
\text { Maps, notebook e retroprojetor; Folha } \\
\text { A4 e caneta para quadro branco; } \\
\text { Imagens do aplicativo Google Earth em } \\
\text { apresentações de slide e retroprojetor; }\end{array}$ \\
\hline $\begin{array}{c}\text { Escala e representação gráfica } \\
\text { do relevo; }\end{array}$ & $\begin{array}{l}\text { Campo minado com perguntas e e } \\
\text { respostas; }\end{array}$ & $\begin{array}{l}\text { Perguntas e respostas sobre os } \\
\text { conteúdos, balóes com as perguntas } \\
\text { dentro, fita adesiva e um dado; }\end{array}$ \\
\hline
\end{tabular}

\footnotetext{
${ }^{1}$ Segundo Moran (2018), “A aprendizagem é ativa e significativa quando avançamos em espiral, de níveis mais simples para mais complexos de conhecimento e competência em todas as dimensões da vida. Esses avanços realizam-se por diversas trilhas com movimentos, tempos e desenhos diferentes, que se integram como mosaicos dinâmicos, com diversas ênfases, cores e sínteses, frutos das interações pessoais, sociais e culturais em que estamos inseridos".
} 


\begin{tabular}{|c|c|c|}
\hline A Terra no Sistema Solar; & Elaboração de geoides; & $\begin{array}{l}\text { Livros e revistas velhas, papel A4, tinta } \\
\text { guache e pincel; }\end{array}$ \\
\hline $\begin{array}{l}\text { História da Terra; Teoria da } \\
\text { deriva continental e das placas } \\
\text { tectônicas; }\end{array}$ & $\begin{array}{l}\text { Maquete do } \\
\begin{array}{l}\text { Elaboração e } \\
\text { vulcões; }\end{array}\end{array}$ & $\begin{array}{l}\text { Bolas de isopor em tamanhos diferentes, } \\
\text { folha de isopor grande, palitos de } \\
\text { madeira e tinta guache; Argila, água, } \\
\text { cerâmica, tinta guache, detergente e } \\
\text { vinagre; }\end{array}$ \\
\hline $\begin{array}{ll}1^{\circ} \text { Encontro das Licenciaturas } \\
\text { da Universidade } & \text { Estadual de } \\
\text { Alagoas - } & \text { PIBID e } \\
\text { RESIDÊNCIA } & \\
\text { PEDAGÓGICA; } & \end{array}$ & $\begin{array}{l}\text { Exposição das atividades } \\
\text { elaboradas até o momento pelos } \\
\text { residentes e pibidianos no campus } \\
\text { da UNEAL; }\end{array}$ & Van para transporte dos alunos. \\
\hline
\end{tabular}

Fonte: Elaborada pelos autores, 2021.

Diversas atividades foram realizadas ao longo do projeto, e todas elas baseadas e voltadas para a realidade de cada indivíduo que participou das aulas, seja exemplificando os assuntos e os moldando para a realidade deles em seu espaço vivido, ou seja, mostrando o lugar que eles pertencem, por meio das paisagens e da cartografia. Todos os materiais usados no quadro acima poderão ser analisados com maiores detalhes nos resultados. A sala de aula é um laboratório e as ações devem ser lidas como uma constante pesquisa/ação (CASTROGIOVANNI e ABREU E SILVA, 2020), é importante se desdobrar e inovar em cada aula. Cada professor reconstrói a geografia à sua maneira (SIMIELLI, 2015), com suas práticas e suas habilidades adquiridas durante seu tempo como docente, para proporcionar o melhor aos alunos.

\section{Paisagem, Lugar e Cartografia como eixos da geograficidade em uma turma de $6^{\circ}$ ano da Escola Municipal João Costa de Oliveira, União dos Palmares/AL}

Durante todo o projeto foi usado um método que proporcionasse aos alunos uma melhor compreensão dos conteúdos, fazendo um link com a realidade do espaço vivido por eles. No presente artigo abordaremos um pouco sobre Paisagem e Lugar como categoriaschave do processo do fazer geográfico, com uso por diversas vezes da cartografia, ou como Dardel chamava, geograficidade ${ }^{2}$, a relação concreta do homem com o meio, resultando em seu modo de existência experiencial.

A Paisagem é a dimensão espacial da percepção; trata-se de um processo seletivo de apreensão humana no qual cada indivíduo tem sua visão de mundo. Dentro desta perspectiva, é de suma importância os sentidos como visão, audição, tato, paladar e olfato, que possibilitam ao humano a vivência do que chamamos de espaço experiencial. O Lugar

\footnotetext{
${ }^{2} 2015$, p. $1-2$.
} 
é centro gerador de significados ${ }^{3}$, organizando o espaço ${ }^{4}$ por meio da diversidade de percepções, senso de familiaridade e pertencimento. Para Merleau-Ponty, 2011:

O espaço vivido é a condição sem a qual não se pode pensar a plenitude da objetividade, e é verdade que, se tentarmos tematizar vários espaços, eles se reduzem à unidade, cada um deles encontrando-se em uma certa relação de posição com os outros e, portanto, sendo uma e a mesma coisa que eles. (MERLEAU-PONTY, 2011, p. 297)

Por plenitude da objetividade, entendemos o processo de vivência dos alunos da Escola Municipal João Costa de Oliveira, bem como a compreensão basilar sobre paisagem e lugar, como categorias geográficas que são eixos da construção que chamamos de espaço vivido; a cartografia também se apresenta com grande importância, e segundo CASTROGIOVANNI e ABREU E SILVA (2020, p. 53), o ensino da Geografia se torna eficaz quando associado à Cartografia, pois, a Geografia se utiliza da construção da espacialidade cartográfica como metodologia para a construção de seu conhecimento.

Os detalhes das experiências no projeto serão apresentados a seguir:

- Na atividade 01, tratamos sobre Espaço e Paisagem. De forma dinâmica, levamos imagens tiradas da internet em formato de quebra-cabeças, com recursos próprios, para que os alunos montassem e descobrissem de onde eram as paisagens trabalhadas e, a importância para o município de União dos Palmares. Cada imagem foi selecionada propositalmente por nós: a Escola Estadual Rocha Cavalcante, a mais antiga da cidade; a Serra da Barriga, que durante décadas abrigou centenas de negros fugitivos da escravidão; e a Escola Municipal João Costa de Oliveira, que é um lugar importante do cotidiano deles. Para Batista e Pinheiro (2019):

O professor precisa buscar na realidade do aluno o viés para conhecer o mundo próximo a ele, mas também o mundo distante, ou seja, do local para o global e vice-versa. Precisamos ser essa ponte que liga o conhecimento cientifico à realidade do aluno e ao cotidiano escolar. É necessário o uso de experiências concretas, tendo o professor como o mediador desse processo". (BATISTA; PINHEIRO, 2019, p. 70)

Ao identificar todas as imagens, os alunos colaram os quadrinhos com cola branca em folha de papel A4 e colamos em uma folha de papel 40, criando um cartaz. Questionamentos sobre o significado dos lugares para o município e para eles, por questões

\footnotetext{
${ }^{3}$ Holzer, 1998, p. 74-75.

${ }^{4}$ Bollnow, 2008, p. 62.
} 
de pertencimento ou não, foram realizadas e, continuamos a aula com indagações de como identificar espaços.

Figuras 3 e 4 - Atividades sobre o conteúdo Espaço e Paisagem - construção de quebra cabeças e cartazes com imagens de paisagens da cidade
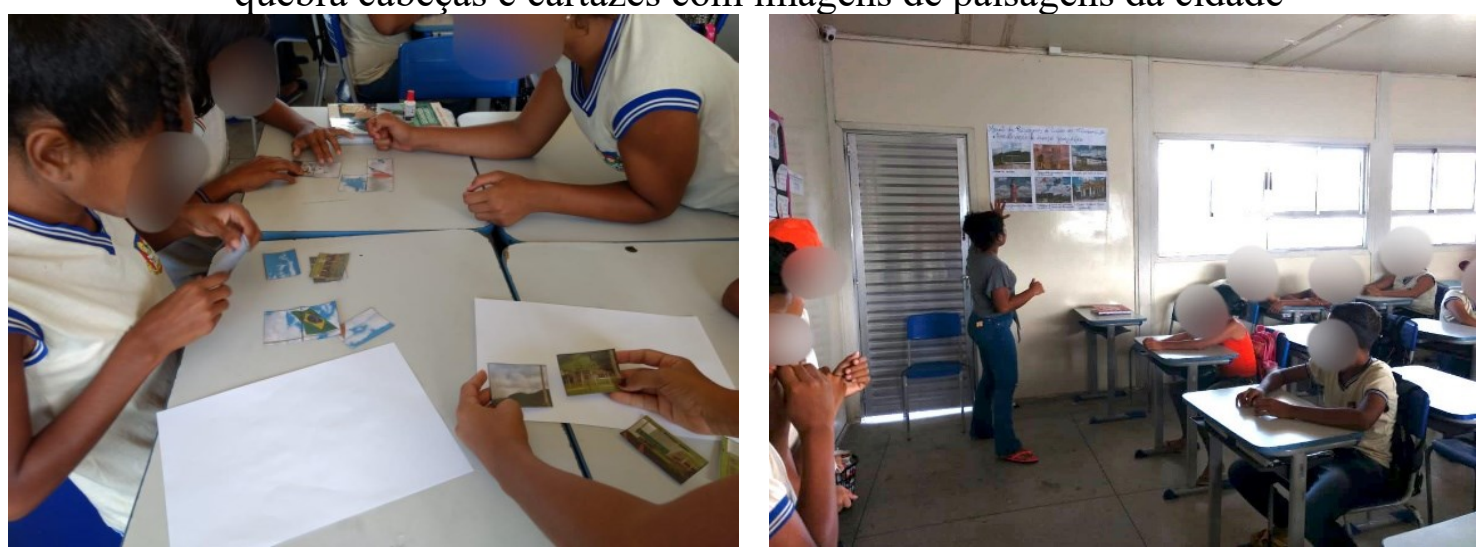

Fonte: Arquivo dos autores, 2019.

- Para a Orientação no Espaço, criamos uma bússola caseira com os alunos, produzida por materiais básicos que temos acesso em casa e foi um encanto para os mesmos. A atividade 02 foi realizada com o uso de um recipiente com água, agulha, papel higiênico e lã de aço, possibilitando-nos mostrar aos alunos como identificar o centro magnético da Terra, e comprovamos comparando com uma bússola convencional de celular.

Os próprios alunos criaram suas bússolas em grupos e foi uma experiência proveitosa. Para ampliar os horizontes, ensinamos como desenhar uma rosados-ventos no quadro branco, explicando como podemos nos guiar por meio dela e mostrando que existem diversas formas para que possamos nos localizar, reforçando a ideia de que é possível e de que todos nós estamos num lugar e estabelecemos um grande número de relações espaciais ao mesmo tempo (KAERCHER, 2019), por isso, em alguma ocasião da vida iremos precisar de algum tipo de localizador. 
Figuras 5 e 6 - Atividades sobre os conteúdos Orientação no Espaço - Construção de bússola geográfica
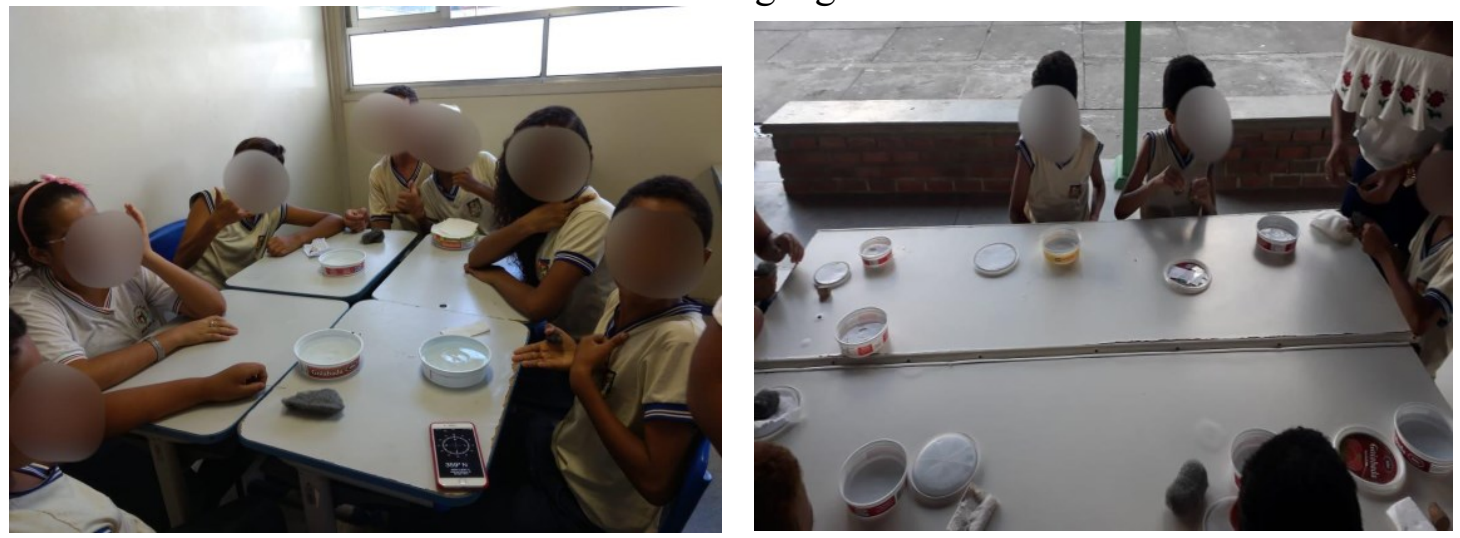

Fonte: Arquivo dos autores, 2019.

- Para explicar a Cartografia, ciência e arte da representação gráfica da superfície terrestre que instrumentaliza o sujeito a diferentes leituras, e o seu produto final é o mapa (CASTROGIOVANI e ABREU E SILVA, 2020), o que são os mapas e como usa-los em seus cotidianos, na atividade 03 foram usados diversos tipos de mapas encontrados na escola e aplicativos de celular como o Google Maps. Dessa forma, os alunos tiveram noção do uso da Cartografia de forma ampla, aplicada no dia a dia de forma simples e atualizada, com exibição de mapas de diversos tipos e para diversos usos.

Foram elaborados Mapas Mentais pelos alunos com os percursos de suas casas até a escola, e logo em seguida, utilizamos o aplicativo Google Earth como ferramenta de localização, digitando o nome da cidade na lupa de busca. Ao encontrarmos a cidade de União dos Palmares, buscamos o bairro no qual se encontra a Escola Municipal João Costa de Oliveira. Convidamos alguns alunos para que pudessem identificar o ponto de localização de suas casas.

A atividade seguiu a mesma objetividade inicial: fazer com que os alunos reconhecessem o lugar como essência vinculada ao teor do pertencimento; ou como diria TUAN (2013, p. 167), "O espaço transforma-se em lugar à medida que adquire definição e significado", sendo o lugar um mundo de significado organizado. 
Figuras 7 e 8 - Atividades do conteúdo Cartografia - Elaboração de mapas mentais usando a ferramenta do Google Earth
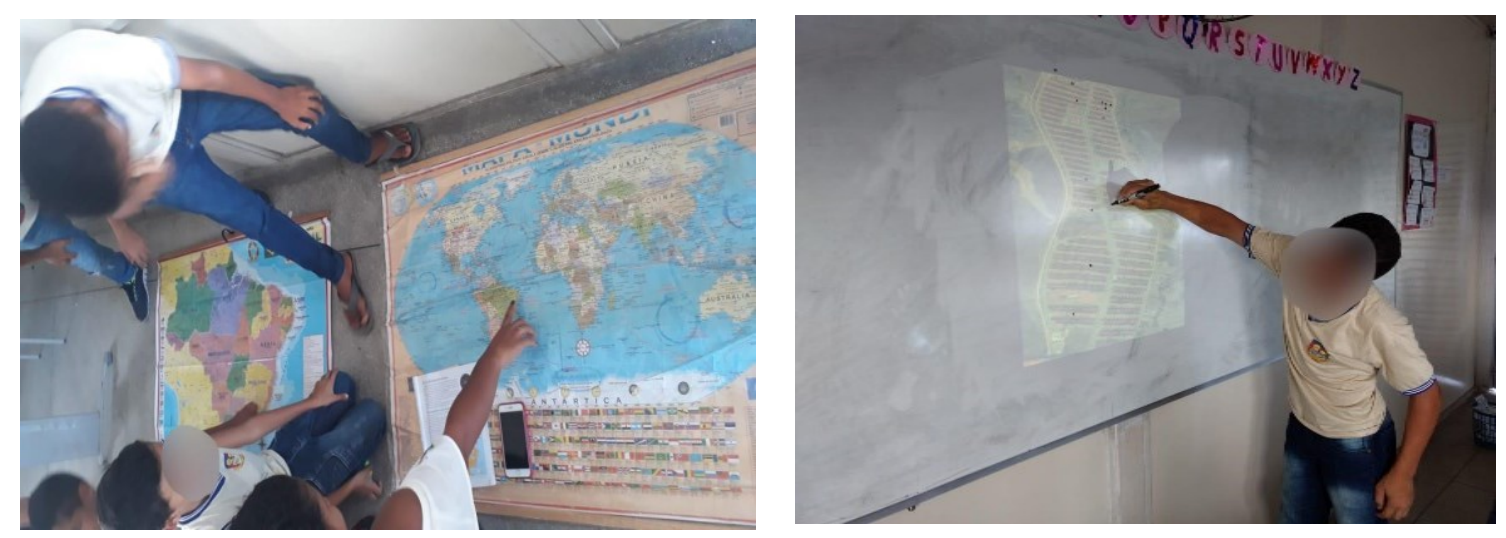

Fonte: Arquivo dos autores, 2019.

- Na atividade 04 foi elaborado um Campo Minado, uma aula lúdica e atrativa. Se faz necessário ter sensibilidade para enxergar e fazer Geografia, principalmente nos anos iniciais. A geografia é importante para nós, mas nada garante que nossos alunos tenham a mesma atenção por ela (KAERCHER, 2019. p, 18).

A sala de aula deve ser um espaço de construção e de troca de conhecimentos, onde se ensina e se aprende. Diferentemente do que pensam alguns profissionais, mesmo professores com domínio de conteúdo da disciplina sempre aprendem ao ensinar. O professor é o parceiro mais importante no processo de aprendizagem, pois ele pode incitar o grupo de alunos ao aprendizado, desafiá-los a serem pesquisadores permanentes, como também ser o responsável pela amputação intelectual, desistência e desânimo de uma turma inteira (MOREIRA, SILVA e FERREIRA, 2015). Por isso, se faz necessário inovar a cada dia, para que aja maior interação e troca de conhecimentos entre professor e aluno.

O Campo Minado ficou exposto no chão em forma de tapete, composto por bexigas que continham perguntas sobre todas as representações cartográficas da Terra e formas de relevo, conteúdos lecionados anteriormente, para que os alunos respondessem em forma de revisão e se divertissem com o jogo. O tapete pertencente a professora regente e as bexigas foram adquiridas com recursos próprios. A sala foi dividida em dois grupos, eles se dividiram entre si para obter melhores resultados e ganhou o grupo que obteve mais acertos. Uma rica experiência, que inclusive foi usada em outras turmas e outras escolas com o projeto. 
Figuras 9 e 10 - Atividade do conteúdo Cartografia - Jogo do Campo Minado
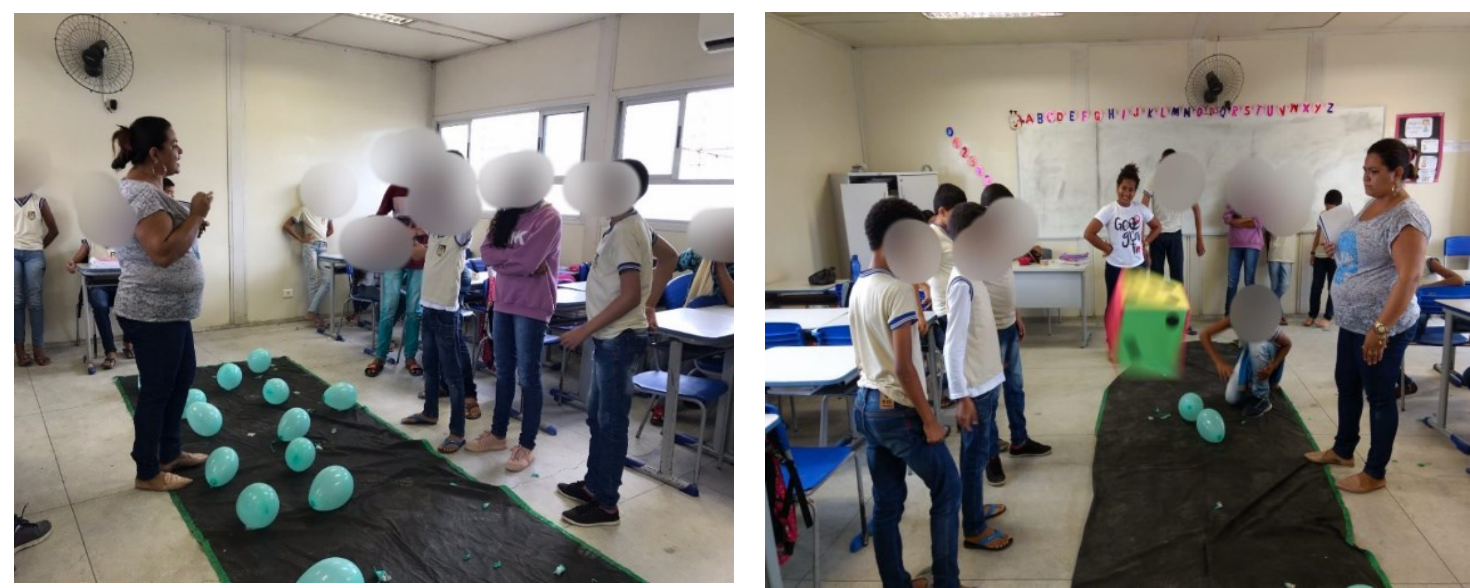

Fonte: Arquivo dos autores, 2019.

- A atividade 05 foi composta através de papeis antigos, folhas A4, tinta guache e pinceis, adquiridos com recursos próprios dos residentes, para elaboração de geoides, a forma mais próxima à realidade física da Terra. De acordo com PASSINI (2015, p.148) o ensino de geografia e o de cartografia são indissociáveis e complementares: a primeira é conteúdo e a outra é a forma.

Não faz sentido tratar de localização espacial e uso da cartografia sem mostrar o espaço onde todas as interações acontecem, no planeta Terra. Usar formas dinâmicas invés do convencional livro didático, convidar os alunos para construir os materiais a serem usados na aula é fazer com que eles construam o próprio processo de aprendizagem, dando a sua importância e valor a cada novo experimento elaborado. Os alunos gostam de interagir com o mundo, de usar a imaginação e aprender ludicamente.

O saber cartográfico para os discentes, seja de séries iniciais ou até mesmo nas salas de aula universitárias são fundamentais, deve estar presente na formação integral do educando, não podemos pensar isoladamente essa ciência das demais, devendo ser considerado também o saber cartográfico a ser ensinado, principalmente aquele presente nos livros didáticos, entre outros. 
Figuras 11 e 12 - Atividade do conteúdo Abordando o Planeta Terra - Elaboração de geoides
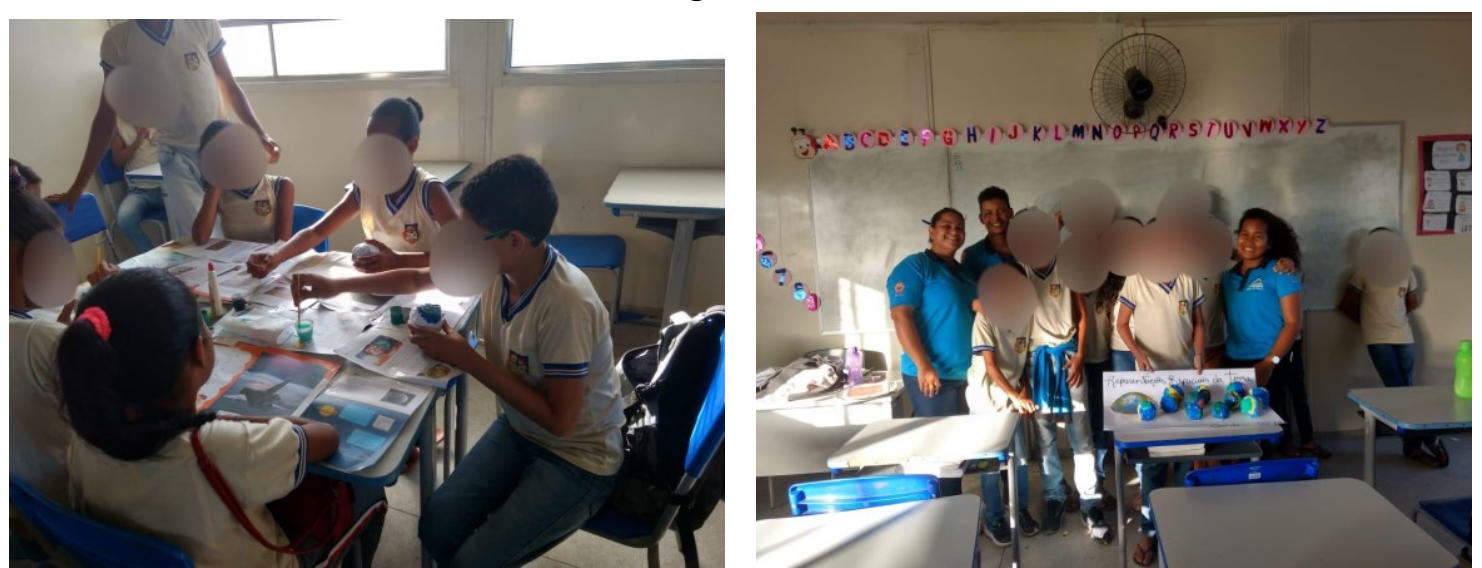

Fonte: Arquivo dos autores, 2019.

- A atividade 06 foi realizada para dar continuidade aos assuntos abordados sobre o planeta Terra, com exposição de uma maquete do Sistema Solar. Elaborada pelos residentes do projeto, por meio de recursos próprios, com bolinhas de isopor, tinta guache e palitinhos, para mostrar como ele funciona de uma forma mais próxima do real. SIMIELLI (2015, p. 94) afirma que o aluno, por sua vez, constrói ele mesmo seu saber, retendo apenas uma parte dos conteúdos propostos, integrando-a à sua maneira nos esquemas de pensamento e ação. Por isso, é necessário buscar diferentes formas do saber geográfico

E elaboração de vulcões pelos alunos, com tábuas ou cerâmicas para servir de base, argila, água, tinta, detergente e vinagre. Os vulcões serviram para mostrar aos alunos o que acontece no interior da Terra, o magma, suas erupções e a formação dos novos relevos derivados destes acontecimentos.

Figuras 13 e 14 - Atividades do conteúdo Abordando o Planeta Terra Construção de maquete do sistema solar e vulcão
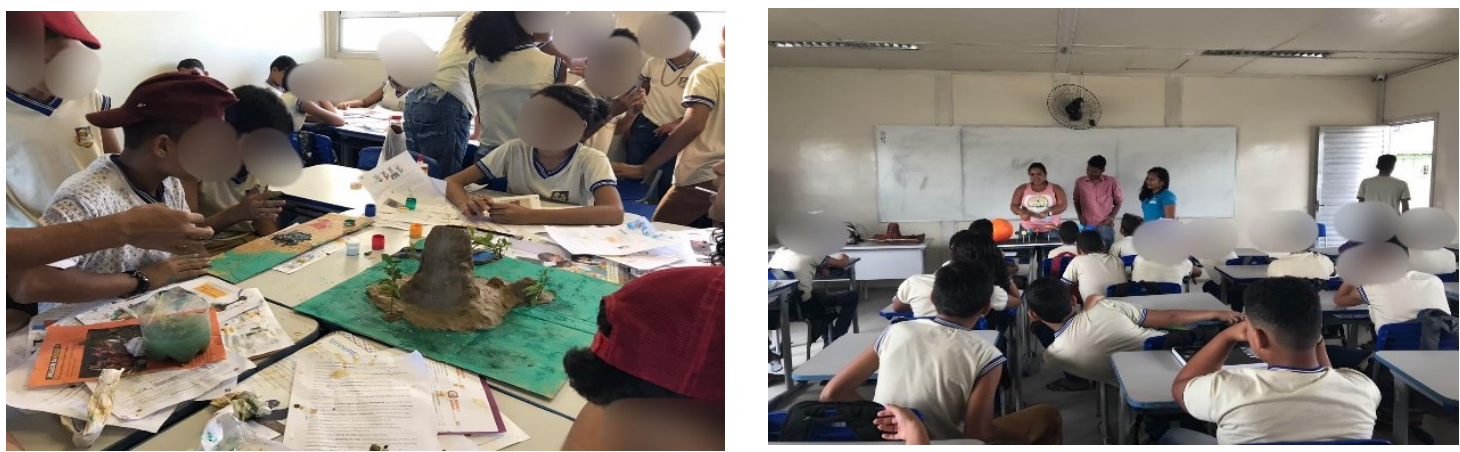

Fonte: Arquivo dos autores, 2019.

- A última atividade do presente artigo, foi uma atividade extraclasse, onde conseguimos a autorização da escola para levarmos os alunos à exposição do $1^{\text {o }}$ 
Encontro das Licenciaturas da Universidade Estadual de Alagoas - PIBID e RESIDÊNCIA PEDAGÓGICA, no campus V. Não conseguimos levar todos os alunos que participavam do projeto Residência Pedagógica, a escola não teve como ofertar um transporte que comportasse todas as turmas. Alugamos uma van com recursos próprios, fizemos uma seleção entre os alunos e os levamos até o campus. Conhecer um Campus Universitário e ver as atividades realizadas em sala de aula por eles em forma expositiva foi de grande importância para os alunos e seus planos para o futuro. O Campus V da Universidade Estadual de Alagoas conta com um museu, o Espaço de Memória Artesã Irinéia Rosa, recheado de obras da artista que o museu leva o nome e de artistas locais. Os alunos conheceram o museu, o primeiro a ser visitado na vida deles.

Tirar crianças de uma sala de aula rotineira e apresenta-las como funciona o ensino superior e a grandiosidade da disciplina, faz surgir um encanto deles pela disciplina e a certeza de que eles são capazes de dominar saberes além das salas de aula da Escola Municipal João Costa de Oliveira.

Figuras 15 e $16-1^{\circ}$ Encontro das Licenciaturas da Universidade Estadual de Alagoas - PIBID e RESIDÊNCIA PEDAGÓGICA
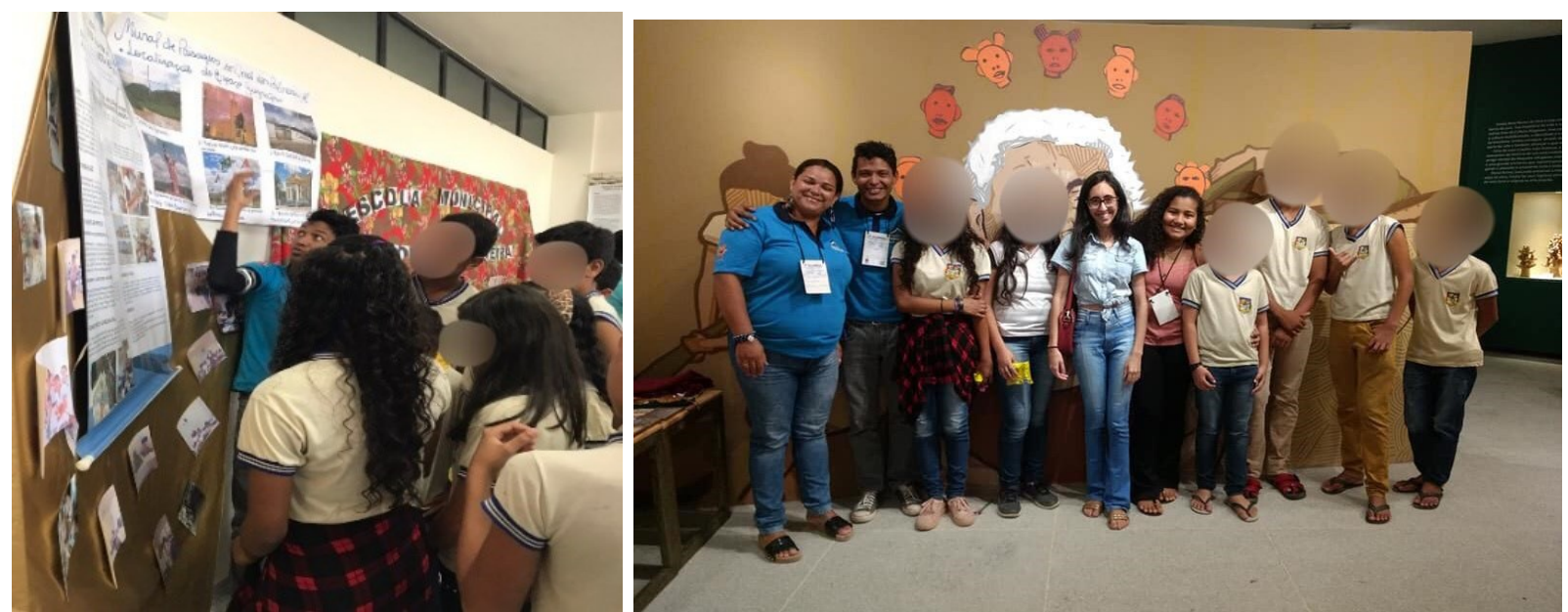

Fonte: Arquivo dos autores 2019.

\section{CONSIDERAÇÕES FINAIS}

Todas as experiências em sala foram maravilhosas, cada qual com sua finalidade, nos mostrou que o ensino deve ter como ponto de partida o espaço vivido dos alunos, sua cidade, seu bairro, sua escola, seu lar. Toda a ideia que a geograficidade nos traz. O diálogo de que aluno que não tem condições de vida estável não tem êxito, é uma falácia. O que 
falta no meio educacional, principalmente nos anos iniciais, é o lúdico, técnicas que motivem os alunos a conhecer os conteúdos, saindo da mesmice e do livro didático de sempre. Por mais acumulativo e cansativo que seja o trabalho do professor, se faz necessário olhar para a Geografia com encanto, para ensinar com encanto.

As atividades planejadas e praticadas durante todo o projeto foram além das nossas expectativas como residentes e além das competências da Base Nacional Comum Curricular, criamos novas formas de aprendizagem para os alunos e motivamos professores regentes a inovarem seus currículos e suas formas de ensinar. Mesmo com todas as dificuldades encontradas e a limitação da escola com falta de materiais básicos, como livros didáticos, retroprojetores, notebooks e transporte para atividades extraclasse, fomos além.

Os alunos são movidos pelo que veem, dinâmicas que impulsionam o imaginário geográfico os levam a questionamentos de significado/significância dos elementos ao seu redor, e devem ser sempre usados. Aprender de maneira lúdica faz entender que a Geografia não é "chata", mas que ela sempre está presente no cotidiano de todos, em diversas formas, precisando de um pouco de atenção.

O Projeto Residência Pedagógica é de suma importância na vida dos discentes das licenciaturas, que deve ser olhado com mais atenção e obter mais investimentos para a educação nacional. É um preparatório para a vida na docência, proporcionando experiências únicas, servindo de aprimoramento acadêmico e pessoal. Projeto que o Ministério da Educação deve continuar ofertando para as instituições de Ensino Superior, independente do momento que o país estiver passando, é com a Educação que as coisas evoluem e evoluímos diariamente. Ensinar, também é aprender. Não podemos parar.

\section{REFERENCIAS}

BATISTA, A. N. C.; PINHEIRO, A. C. O estudo do lugar nas práticas educativas dos professores de geografia. IN: Formação de professores, metodologias e ensino de geografia / Org. Antonio Carlos Pinheiro e Wellington Alves Aragão. - 1. Ed. - Goiânia: Editora Espaço Acadêmico, 2019.

BACICH, L.; MORAN, J. Metodologias ativas para uma educação inovadora: uma abordagem téorico-prática [recurso eletrônico] / Organizadores, Lilian Bacich, José Moran. - Porto Alegre: Penso, 2018. 
CASTROGIOVANNI, A. C. A construção do conhecimento cartográfico nas aulas de geografia [recurso eletrônico] / Antonio Carlos Castrogiovani, Paulo Roberto Florêncio de Abreu e Silva. - Goiânia: C\&A Alfa Comunicação, 2020.

DARDEL, E. O homem e a terra: natureza da realidade geográfica. - Tradução Werther Holzer. - São Paulo: Perspectiva, 2015.

GATTI, B. A. Atratividade da carreira docente no Brasil. Fundação Carlos Chagas. São Paulo, 2009.

HOLZER, W. Paisagem e lugar: um estudo fenomenológico sobre o Brasil do século XVI. - São Paulo, 1998 (Tese de Doutorado).

KAERCHER, N. A. A Geografia serve para entender a água, o sangue, o petróleo... serve para entender o mundo, e, sobretudo, a nós mesmos! A formação docente em geografia: teorias e práticas / Org. Paulo Sérgio Cunha Farias, Marlene Macário de Oliveira. - Campina Grande: EDUFCG, 2014.

MERLEAU-PONTY, M. Fenomenologia da percepção. Tradução Carlos Alberto Ribeiro de Moura. - 4.Ed. - São Paulo: Editora WMF Martins Fontes, 2011.

MOREIRA, D. S.; SILVA, M. J.; FERREIRA, R. J. A didática da afetividade. Prática de ensino de geografia e estágio supervisionado / Org. Elza Yasuko Passini, Romão Passini, Sandra T. Malysz. - 2. Ed., $3^{\text {a }}$ reimpressão. - São Paulo: Contexto, 2015.

PASSINI, E. Y. Alfabetização Cartográfica. Prática de ensino de geografia e estágio supervisionado / Org. Elza Yasuko Passini, Romão Passini, Sandra T. Malysz. - 2. Ed., $3^{\text {a }}$ reimpressão. - São Paulo: Contexto, 2015.

OLIVEIRA, M. M. O processo de ensino-aprendizagem na Geografia: uma revisão necessária. A formação docente em geografia: teorias e práticas / Org. Paulo Sérgio Cunha Farias, Marlene Macário de Oliveira. - Campina Grande: EDUFCG, 2014.

SILVA, A. C.; CAMARGO, E. A construção do conhecimento moral. Prática de ensino de geografia e estágio supervisionado / Org. Elza Yasuko Passini, Romão Passini, Sandra T. Malysz. - 2. Ed., $3^{\text {a }}$ reimpressão. - São Paulo: Contexto, 2015.

SIMIELLY, M. E. R. Cartografia no ensino fundamental e médio. A geografia na sala de aula / Org. Ana Fani A. Carlos. - 9. Ed., 3ª reimpressão. - São Paulo: Contexto, 2015.

TARDIF, M. Os professores enquanto sujeitos do conhecimento: subjetividade, prática e saberes no magistério. In: CANDAU, V. M (Org.). Didática, currículo e saberes escolares. Rio de Janeiro: DP\&A, 2000.

TUAN, Y. Espaço e lugar: a perspectiva da experiência. - Tradução: Lívia de Oliveira. - Londrina: Eduel, 2013. 